\section{Pancreatitis Associated with Valproic Acid Therapy for Epilepsy}

David L. Coulter, MD, and Richard J. Allen, MD

Valproic acid is useful for absence, myoclonic, and grand mal seizures and adjunctively for mixed seizures [3]. The drug has been well tolerated in most patients, but vomiting, rashes, hair loss, leukopenia, and thrombocytopenia have been observed. Seven patients have developed hepatitis, which was fatal in $6|5|$. We recently treated a child who developed pancreatitis in direct association with valproic acid therapy.

An 8-year-old boy with myoclonic and akinetic seizures was taking phenytoin, $150 \mathrm{mg}$ per day $(6.4 \mathrm{mg} / \mathrm{kg} / \mathrm{day})$, valproic acid, $1,500 \mathrm{mg}$ per day $(64.4 \mathrm{mg} / \mathrm{kg} / \mathrm{day})$, and clonazepam, $1.5 \mathrm{mg}$ per day $(0.06 \mathrm{mg} / \mathrm{kg} /$ day $)$. Intermittent vomiting developed and the serum glutamic oxaloacetic transaminase (SGOT) level rose to twice normal. At $81 / 2$ years of age, in February, 1979, he was hospitalized with lethargy, vomiting, and abdominal pain.

He was afebrile and normotensive. A maculopapular rash was present. The abdomen was tense and bowel sounds were decreased. He was lethargic, and there was a right-sided Babinski sign. Laboratory data included calcium, $8.9 \mathrm{mEq} / \mathrm{L}$; white blood cell count, 39,000; SGOT and serum glutamic pyruvic transaminase, twice normal levels; and amylase, 1,125 Somogyi units (normal, less than 150 units). The phenytoin level was $4.4 \mu \mathrm{g} / \mathrm{ml}$ and valproic acid, $72 \mu \mathrm{g} / \mathrm{ml}$. A urine drug screen was negative.

Phenytoin was continued intravenously but valproic acid and clonazepam were discontinued. Abdominal ultrasound examination showed diffuse pancreatic enlargement with no fluid collection and normal gallbladder and liver. Mumps titer was less than 1:8. A left thoracentesis yielded $80 \mathrm{ml}$ of serous fluid with an amylase level of 4,000 units. Over the next three days the abdomen became less tense and the serum amylase fell to 135 units. He was discharged asymptomatic on the twelfth hospital day, taking only phenytoin, $200 \mathrm{mg}$ per day. When seizures recurred, valproic acid was restarted and cautiously increased to $500 \mathrm{mg}$ per day. Blood counts, SGOT, and repeated amylase levels were normal and the electroencephalogram was much improved.

Three months later he again developed recurrent vomiting and abdominal pain. He was afebrile and normotensive. The abdomen was soft and bowel sounds were normal, but there was moderate tenderness and guarding. White blood cell count was 17,100 and serum amylase level, 2,000 units. Phenytoin was continued intravenously

From the Section of Pediatric Neurology, Department of Pediatrics and Communicable Diseases, and the Department of Neurology, University of Michigan Medical Center, Ann Arbor, MI 48109.

Accepted for publication Aug 19, 1979. and valproic acid was discontinued. By the fifth hospital day, amylase was 269 units. Abdominal ultrasound on the seventh day showed a normal pancreas, and an oral cholecystogram was normal. Seizures were subsequently controlled with phenytoin and phenobarbital. He was discharged asymptomatic on the ninth hospital day with a normal amylase level and four months later was still well.

Drugs associated with pancreatitis include thiazide diuretics, furosemide, ethacrynic acid, chlorthalidone, acetaminophen, phenformin, propoxyphene, clonidine, tetracycline, rifampin, azathioprine, asparaginase, oral contraceptives, corticosteroids, and adrenocorticotropic hormone [1a]. The patient reported here had taken none of these drugs, and a urine drug screen was negative. Other common causes of pancreatitis include cholelithiasis, trauma, surgery, mumps, hyperparathyroidism, hyperlipidemia, aminoaciduria, hemochromatosis, and alcoholism [4]. Most of these diseases are rare in children and were excluded in our patient.

Our patient recovered from the first episode of pancreatitis while taking phenytoin alone, suggesting that this drug was not the cause of his illness. Three months later, reinitiation of valproic acid was associated with a recurrence of pancreatitis. The second episode also cleared while he was taking phenytoin but without valproic acid. The present evidence suggests that pancreatitis was associated with the use of valproic acid. We have measured serum amylase levels in more than 20 additional children taking valproic acid in conjunction with other anticonvulsants and have discovered no elevations thus far, suggesting that this must be an unusual complication of valproic acid therapy. However, 3 other patients have recently been reported who developed pancreatitis from valproic acid $[1,2]$.

\section{Addendum}

Since we submitted this report, a 10 -year-old girl from our clinic, treated with valproic acid alone at $30 \mathrm{mg}$ per kilogram per day for three months, developed recurrent vomiting with an elevated serum amylase level. She died following laparotomy that demonstrated hemorrhagic pancreatitis.

\section{References}

1. Batalden PB, Van Dyne BJ, Cloyd C: Pancreatitis associated with valproic acid therapy. Pediatrics 64:520-522, 1979

1a. Bourke JB, Mead GM, McIllmurray MB, et al: Drugassociated primary acute pancreatitis. Lancet 1:706-708, 1978

2. Camfield PR, Bagnell P, Camfield CS, et al: Pancreatitis due to valproic acid. Lancet 1:1198-1199, 1979

3. Jeavons PM, Clark JE, Maheshwari MC: Treatment of generalized epilepsies of childhood and adolescence with sodium valproate. Dev Med Child Neurol 19:9-25, 1977

4. Snodgrass PJ: Diseases of the pancreas, in Harrison's Principles of Internal Medicine. Seventh edition. New York, McGrawHill, 1974, chap 302, pp 1571-1574

5. Suchy FJ, Balistreri WF, Buchino JJ, et al: Acute hepatic failure associated with the use of sodium valproate. $N$ Engl J Med 300:962-966, 1979 